\title{
Understanding and analysing activity and learning in virtual communities
}

\author{
F. Henri \& B. Pudelko
}

\begin{abstract}
The purpose of this study is to provide a preliminary framework to observe, analyse and evaluate both activity and learning in virtual communities. So various types of virtual communities will be studied by examining their relationship to socialisation and learning. After a presentation of the main ideas of Wenger's social learning theory, the principal components of the social context of the emergence and evolution of virtual communities will be described. It will show how taking this context into account enables the definition of four principal types of virtual communities: community of interest, goal-oriented community of interest, learners' community and community of practice and describe how the activity of these communities develops according to the goals they set for themselves and to the strategies they adopt to reach them. For each type of virtual community, an attempt will be made to determine the process of negotiation of meaning at the base of learning, and to describe the learning performed in terms of participation and reification processes.
\end{abstract}

Keywords: Asynchronous; Collaboration; Learning; Negotiation; Peer, Socialization; Virtual communities

\section{Introduction}

The social appropriation of information and communication technologies brings into existence in cyberspace various shapes of gatherings, regrouped under the common designation of virtual communities. Tools such as discussion forums and chat, environments like MUDs and MOOs or Web sites are devices that support the existence of these social entities.

From a social perspective, studies on virtual communities examine the relationships and the social values conveyed by the notion of community. Certain authors question the fact that communities can exist in a virtual mode, since for them the concept of community cannot be dissociated from a common physical space and from a history shared by its members, two elements on which complex social relationships are based (Breton, 1995; Weinreich, 1997). For other authors, virtual life is an established fact and the destiny of human society is from now on dependent on it. Virtual communities exist and play a socialisation role to the same extent as 'real' communities do (Rheingold, 1993; Lévy, 2000). They carry values of an ideally harmonious society.

From an educational perspective, research on virtual learning communities is

Accepted 2 October 2002

Correspondence: Dr. France Henri, Centre de recherche LICEF, Télé-université du Québec, 4750, avenue Henri-Julien, Montréal, Québec, Canada H2T 3E4

Email: france_henri@teluq.uquebec.ca 
polarised around two positions. Some question the validity of the notion of a virtual community (Hung \& Chen, 2002) whereas others, without questioning it, investigate its pedagogical potential and implementation. The activity of virtual participants in communities is sometimes described in terms of formal or informal learning (Trentin, 2001) or of socialisation or professional identity development (Gordin et al., 1996), and learning may be regarded as a by-product of activity (Nichani \& Hung, 2002).

The different perspectives adopted for research on virtual communities, as well as the discrepancies and inconsistencies in research results, suggest that a theoretical framework is needed to better understand these entities and their relationships to socialisation and learning. More precisely, such a framework should help to recognise the characteristics and the diversity of virtual communities, to grasp the processes underlying their activity and to better evaluate the different types of learning they induce. From that perspective, the purpose of this paper is to describe four forms of virtual communities that have been identified, and to find preliminary reference marks to observe, analyse and evaluate both activity and learning in virtual communities.

The various types of existing communities will be studied, using the social learning theory of Wenger (1998) to examine their relationship to socialisation and to learning. After a presentation of Wenger's social learning theory main ideas, the principal components of the social context from which virtual communities emerge and evolve will be described. This will show how taking this context into account leads to the identification of the four principal types of virtual communities and will describe how the activity of these communities develops according to the goals they set for themselves and to the strategies they adopt to reach them. For each type of virtual community, an attempt will be made to determine the process of negotiation of meaning at the base of learning, and to describe the learning performed in terms of participation and reification processes. An example illustrating the learning carried out in each type of online community will be given. Finally, concluding comments will briefly indicate the dimensions that the intended theoretical framework should cover.

\section{Learning as participation in virtual communities}

The study of the virtual communities is based on three fundamental tenets of the social learning theory (Wenger, 1998) that are articulated around a central concept, participation in a community life, which provides the basis for learning and identity construction processes.

Firstly, this theory regards community not as an ideal to strive for, but as a reality. It postulates that people gain from taking part since the human being is intrinsically social, all life experience is a social experience in various communities and through active involvement in social endeavours. In fact, everyone takes part in several communities (Wenger speaks of 'multimembership') and this participation usually seems so 'natural' that most of the time, they are not conscious of it. Reciprocally, the participation process results in the construction of communities.

Secondly, this theory allows the simultaneous contemplation of socialisation and learning by considering learning as a social process. Thus participation in a community always leads to learning since it contributes to the construction of identity. Although Wenger mostly describes the learning achieved by the 
participation in a community of practice in a work environment, he stresses that other types of learning and identity construction are generated within other types of community. In fact, people learn while participating in various kinds of communities in various forms.

Thirdly, according to Wenger, negotiation of meaning corresponds to the process at the base of any individual and collective learning. This process, the goal of which is to ascribe meaning to life experience, is composed of both participation and reification processes. On the one hand, participation refers to "the social experience of living in the world in terms of membership in social communities and active involvement in social enterprises' (p. 55). On the other hand, the reification process is one 'of giving form to our experience by producing objects that congeal this experience into "thingness" (p.58). Wenger insists on the fundamental complementarity of these two processes, which are in constant interaction.

The theoretical framework developed by Wenger first leads to a consideration of virtual communities as a reality. Indeed, these entities, independently of the geographical distribution of their members, constitute communities since they correspond to 'social configurations in which our enterprises are defined as worth pursuing and our participation is recognisable as competence' (p. 5). From there, it follows that all virtual communities are learning communities because their members learn while taking part in their activity. Finally, all learning communities are not communities of practice; they undertake and participate in various activities which promote various types of learning. It should be stressed that, in Wenger's approach, the activity does not comprise its own meaning in opposition to what Activity Theory (Engeström, 1987) proposes. Following Wenger, the activity is located in the broader context of socially conducted negotiation processes of meaning which include the social appropriation of ICT.

To determine the various types of learning gained by participation in a virtual community, the unit of analysis is defined as the activity involved in the social context of emergence and evolution of the virtual community.

\section{The activity of virtual communities}

It is possible to identify three principal components of the social context of the activity of virtual communities:

- the emergence of intention (goal of the community);

- the methods of initial group creation and

- the temporal evolution of both the goals and the methods of group creation.

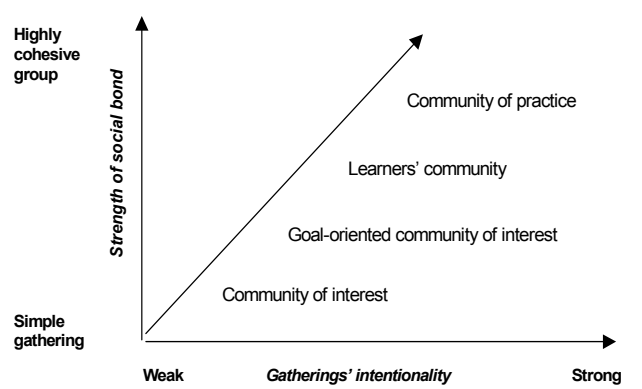

Fig. 1. Different forms of virtual communities according to their context of emergence.
The dynamic and interdependent relationship between these components indicates that the process of creation and evolution of a virtual community is codetermined by the intentionality of the creation of the group and by its nature. This relationship enables the distinction of four principal types of communities, represented in Fig. 1. The vertical axis of this 
figure represents the process of group creation, which differs according to the strength of the social bond between the members within the group and to their involvement in the group. The horizontal axis represents the groups' intentionality that expresses the will, more or less marked, to create a strong social bond and to undertake an activity with a learning goal.

\section{The emergence of intention}

In virtual space, the emergence of a community necessarily takes a formal character and is part of a process of increasing awareness of its existence or of its potentiality of existence. This increase of awareness is concretised by the declaration of the intention of existence of the community (and eventually by the definition of a goal) that is formalised by the listing of its members, by choosing tools of communication, by creating an environment offering various types of resources (information website, databases, collective management and production tools, voting devices, etc.) and by adopting rules of operation. Thus, the existence of a community establishes itself during the social process of appropriation of the resources that support its activity.

\section{Type of group or gathering}

A virtual community projects itself as a social entity that realises the intentions and purposes of the individuals, the groups or the organisations. So to exist it needs the conscious membership of its adherents. During its emergence phase, to a large extent the type of gathering of a virtual community determines the goal it sets for itself. This goal can range from the simple gathering of more or less eager people to engage in a common action to the constitution of a group marked by a high degree of involvement and cohesion (St-Arnaud, 1989). The type of gathering influences the participation that can be described in terms involvement, provision of mutual help and support, sharing of common meanings and affirmation of common identity.

\section{Evolution of intention and gathering}

The activity of a virtual community can change according to the evolution of its goal and of the social relationships within the community. This evolution can be related to the participation within the collective activity. The transition from the state of a gathering to that of a group can be regarded as the expression of a stronger social bond, which takes root in the intentionality orienting the activity and in the awareness of belonging to the group.

Thus the activity of the virtual community depends on the type of gathering, the degree of explicitness of the intention justifying the collective action and on the participants' degree of awareness of forming a social learning entity. A certain evolution can take place and lead to the constitution of a more cohesive and more interdependent community motivated towards the attainment of a common target. But it can also go in the other direction and lead to the wearing down of the social bonds and to alteration in the group's mode of operation.

\section{Activity and learning in virtual communities}

The social context of emergence of a community, the evolution of the social bond and the intentionality constitute useful reference marks to understand activity within a community and the learning it induces. Four types of virtual communities are now described by determining their context of emergence, describing the characteristics 
of their activity and tackling the types of learning with which they can be identified.

\section{The community of interest}

Social context of emergence. A community of interest is a gathering of people assembled around a topic of common interest. Its members take part in the community to exchange information, to obtain answers to personal questions or problems, to improve their understanding of a subject, to share common passions or to play. Their synergy cannot be assimilated into that of a formal group motivated by a common goal.

Communities of interest have a variable lifespan. Some appear and disappear at soon after their creation, while others thrive for years. Often they divide into smaller communities that happens on the basis of specialised topics of interest.

Activity. Since the activity of a community of interest does not correspond to a collective endeavour (Benoit, 2000), the members do not systematically expect each other to share their individually appropriated knowledge and do not feel responsible for sharing how they individually use this knowledge. However, a minimum of involvement creates a process of negotiation of meaning, the purpose of which is to reconcile the various perspectives involved. Without this negotiation of meaning, the community can quite simply cease to exist or give birth to a hard core of a few members who will impose their views on others, whose participation will be sporadic and membership transitory (Snow, 1993; quoted by Fischer, 2001).

In order to keep functioning and, consequently, to exist, the community of interest must find a balance in the participation/reification ratio. Thus the need to formalise the knowledge resulting from the interactions is often detected within a community of interest. This need can express itself, for example, by the production of a 'frequently asked questions' (FAQ) document which is used as both a group memory and a marker of community identity.

Learning and identity. The members of this type of community identify themselves more to the topic of interest of the group than to its members. Since the activity is not directed towards the realisation of collective productions or a collective use of common artefacts, the learning that results from the participation in the community consists of knowledge construction, the use of which is more personal than collective. The question of participation, learning and identity construction within communities of interest is complex: it depends on the degree of involvement of people in the community and is conditioned by their diverse loyalties.

An example of a community of interest: Usenet. Usenet newsgroups are a typical example of communities of interest. An analysis by Whittaker et al. (1998) on the activity of 500 newsgroups over a 6-month period shows that the information exchanged between participants of this type of community is actually determined by a central subject, but that the participation ratio is rather weak. Approximately a third of the messages are posted by participants who have made only one contribution, and the average contribution is of approximately three messages per poster. At the same time, these authors found a high degree of cross-posting. Indeed, the volume of transfer of messages from a newsgroup to another was rather significant. In this study, with on average 1319 participants and 4299 messages, each newsgroup overall cross-posted to an average of 272 distinct groups, and an average of $34 \%$ of the messages were addressed to at least one other newsgroup. The regression analysis conducted by 
these authors shows that group interactivity (measured by the number of threads) is positively correlated with the growth of the size of the group, the augmentation of cross-posting, and with the reduction of the size of the messages. This result informs the multimembership developed by the users, who surf between several newsgroups according to their foci of interest, and are consequently inclined to communicate with other groups. This phenomenon tends to indicate that the information exchanged within a group does not constitute a collective inheritance to preserve. It is not 'the exclusive property' of the group and is not the basis of its identity. This interpretation is consolidated by another observation made by these researchers, who indicate that a more regular participation is positively correlated with less cross-posting and the production of longer messages. This seems to indicate that the growth of the sense of belonging to the group and the development of identity results in a reduction of virtual 'nomadism'.

However, Whittaker et al. (1998) notice that the growth of the sense of belonging to the group does not seem to promote greater interaction in the exchanges. The authors observe that, even if $54 \%$ of the newsgroup produced a FAQ - which from their point of view constitutes an improvement of the 'common ground' of the group - this does not seem to foster a more significant negotiation of meaning and to more substantial or richer types of reification. The reification resulting from the FAQ can then be considered as a result of the group activity that is sufficient to sustain the communities defining activity, i.e. the exchange of information, which apparently cannot be equated to 'the enrichment of the meaning produced by the group as a whole'. It seems that this phenomenon can be interpreted within the framework proposed in this paper. In order to change the nature of the activity carried out by a group, the growth of individual involvement must be combined with an increase in common intentionality. Indeed, in the absence of a collective project, the activity of the group remains centred on information exchange.

\section{The goal-oriented community of interest}

Context of emergence. This form of community is not randomly constituted and compares to a task-force or to a project team vested with a specific mandate (Fischer, 2001). It comprises 'expert' individuals, recruited for their competence or their experience, who will share the knowledge and the approaches related to their respective spheres of speciality. This type of community is created to meet specific needs, to solve a particular problem, to define or carry out a project. The lifespan of such communities is fixed and linked to a given mandate. Their survival often depends on available funds, be they external or institutional. They can keep on existing afterwards, transforming themselves into a community of interest, or spawn further goal-oriented communities of interest crystallised around other projects.

Activity. The exchanges of a goal-oriented community of interest take several forms: action centred (what must be done to carry out the project), project oriented topic (main prescribed topic definition and elaboration) and group procedures management. As the members representing varied perspectives have different stakes, they must elaborate common meanings in order to achieve synthesis of their diverse knowledge systems. The process of negotiation of meaning then requires a balance between the participation and the reification of collectively produced knowledge (concepts, tools, 
modification of the problematic situation). The reification can be supported by the collective creation of objects which represent the community's field of intervention.

The goal-oriented communities of interest have to meet a fundamental challenge, which is to build a shared understanding of the task at hand. The pursuit of a common objective requires the possibility for the participants to question, discuss and finally establish the concepts and the objects serving the project. If the project definition is initially fuzzy or ill defined, the community can reformulate it gradually through collaboration. However, if this negotiation of the mandate fails, the members who will not recognise themselves in the project will disengage from it.

Learning and identity construction. The goal-oriented communities of interest identify themselves with their project. Insofar as they manage to benefit from the heterogeneity of the diverse knowledge and competencies of their members, they can exhibit a great capacity for innovation and social creativity.

Although their members can be considered as experts in their field, none has a complete comprehension of the problem at hand. This phenomenon of symmetry of ignorance is proposed by Fischer (2001; quoting Rittel, 1994) as a principal factor of the complexity of the learning performed by the members of a goal-oriented community of interest. Here the learning process is a mutual activity based on the discussion and the creation of intermediary objects allowing the representatives of various knowledge systems to interact and transform the symmetry of ignorance into a resource which supports the group's activity.

An example of goal-oriented community of interest: Learn-Nett. An illustration of the activity of a goal-directed community of interest is the Learn-Nett project (Charlier \& Peraya, 2002) financed by the European Union. This initiative brought together researchers from several fields: educational technology, educational psychology, communication, sociology, economy, data processing, ergonomics. This team gave itself the mandate to develop and implement distance education activities for future teachers, resorting to new technologies to familiarise the apprentice teachers with their use in education. The solution developed by the researchers relied on a network of eight European universities, a research centre and a distance education service. It consisted of a 'life size' creation of an educational unit offered within the framework of a virtual campus offering various tools to support collaborative learning. At the end of the project, the researchers concluded that the community had successfully attained its objective in spite of some difficulties relating to the specificity of the local contexts of implementation of the project. Their activity, within the framework of this specific project, was then terminated.

The researchers brought together by this project constituted a goal-oriented community of interest by the pooling of experiences and because each member contributed her/his various competencies. The realisation of research tasks devoted to the implementation of innovation, such as the development of a virtual campus and the design of initial training of the teachers using learning technologies, led to the collective creation of objects representing the field of intervention of the community (several one day training sessions, research reports, CD-rom, a book (Charlier \& Peraya, 2002; Daele, 2002). These objects testify to the shared meaning they developed of the project. At the end of the project, this community of researchers evolved and transformed its activity. The involvement, the sense of belonging and the common expertise developed by the researchers who played the 
role of tutors in the virtual campus allowed the emergence of a true community of practice, the activity of which ensured the continuity of the project in the five participating universities.

\section{A learners community}

Context of emergence. A learners community is made up of students who may be in the same class, the same institution or geographically dispersed. The creation of this type of community is the first task of a tutor who wishes to induce in his students a learning process based on action, resulting in a project and scaffolded on collaboration between learners (CTGV, 1990; 1993; Koschmann, 1996; Roth, 1996; Laferrière \& Grégoire, 1999; Henri \& Lundgren-Cayrol, 2001). The learners' community thus strongly depends on the tutor.

The learners' community is not perennial because its members are not engaged in a durable way in the activity at the base of its creation. It is born, grows and dies at the rhythm of the stages of an educational program. In this aspect, it does not share the continuous character of the activity which characterises the community of practice in work environment.

Activity. Most of the time, the activity of a learners' community is conceived in terms of knowledge construction and takes root in the learning theories inspired by the sociocognitivist (CTGV, 1990; 1991), constructivist (Papert, 1993) or socioconstructivist approaches (Scardamalia \& Bereiter, 1991), in the theories of activity (Leontiev, 1981; Engeström, 1987), of distributed cognition (Greeno et al., 1996; Pea, 1993) or of situated cognition (Lave \& Wenger, 1990; Greeno \& Moore, 1993).

Knowledge construction occurs during the realisation of projects that value negotiation of meaning and stems from participation as well as from reification. Participation supports the verbal exchanges both around and through the computer (Crook, 1999). Communication takes place between learners of the same class or learners from different institutions or countries, but also with adults representing communities external to the institution, geographically and professionally. Reification, more significant than in a traditional pedagogical situation, generally results in the Web publication of the individual productions and of the common achievements of the learners. These collective works serve to help learners create and maintain group solidarity, to raise their awareness of the division of work and of their responsibility towards the community, and finally to give visibility to the group (Bruner, 1996). Thus: 'People appropriate knowledge when they are given the opportunity to produce knowledge.' (Schwartz, 1999; p.199).

Learning and identity construction. The explicitly declared formal objective of a learners' community is learning. This learning is distinct from that which is performed in the other forms of community because it is guided by an instructor and linked to the disciplinary or transdisciplinary objectives of the curriculum or studies programme. The design of the activity of a learners' community is conceived according to the level of development of the learners and to the institutional context of belonging.

For these reasons, the activity of this type of community cannot be compared to that of a community of practice, as is often the case in the literature. On this point, this study concurs with Barab \& Duffy (2000) who observe that the communities 
created in educational settings are founded on the metaphor of the participation in practice as a means to learn. This teaching strategy allows the learners to be confronted with problems and practices they will meet outside of school and prepares them for their future participation in the real communities of practice.

Since the formal objective of the learners' community is learning, evaluation has a great importance for the teachers and raises intricate problems. How does one reconcile the individual evaluation required by the curriculum with collective evaluation? How does one take into account, from a perspective of integral education, non-disciplinary learning and invest it towards support of personal and social growth? Which criteria must be chosen to evaluate learning carried out in these environments? (Salomon. 2002). Participants in the education system are not the only ones faced with the huge challenge posed by these questions. Researchers are also concerned, as they have to establish the bases of an evaluation methodology. As suggested by Mercer \& Wegerif (1999), this methodology should be supported by the operationalisation of discourse theory and knowledge construction theory through the systematic and complementary use of diverse qualitative and quantitative methods. Only then will proper instrumentation be available for teachers to evaluate learning in learners' communities.

An example of a learners' community: Darwin's World. Le Monde de Darwin or Darwin's World (Aubé \& David, 2000) is a virtual environment which allows learners from eight to 13 years old to acquire skills related to the scientific process: observation, formulation of hypothesis, experimental verification, theory building and communication of results. Its pedagogical strategy is centred on the participation of the pupils and on collaborative work to support the processing and the organisation of information in the manner of a biology researcher. The participation in the activities suggested by Darwin's World consists of the adoption, by a class, of an animal species belonging to regional fauna. This adoption entails a commitment to produce a complete record, describing the identity and the ecology of the species, to be posted on the site of the project. A detailed blueprint is used as a guide to produce the record which automatically becomes part of a common database. The pupils also commit themselves to update the produced record and to take responsibility for answering questions from the public or other researchers. The validation of the record requires consultation, on the one hand, with a specialist of the adopted species and, on the other hand, with a linguistics specialist. These two experts play the role of advisers and partners in the research undertaken by the pupils. A significant part of the exercise resides in the involvement of the pupils to ensure the communication and the diffusion of the information about the adopted species. This communication can be enriched by correspondence with other classes carrying out research on species within the same ecosystem. The children thus take part in a vaster network of exchanges, which reflects the very essence of the production of scientific knowledge and the way in which it progresses.

Initiated, adapted and supervised by the teacher, the activity carried out in Darwin's World invites the children in a progressive process of involvement with the development of scientific method and knowledge. The work entrusted to them brings them to identify with a community of researchers whose participation implies a significant share of communication and negotiation which leads to the reification of knowledge (production, validation and publication on the Web of descriptive records about the animals under investigation). 


\section{The community of practice}

Context of emergence. A community of practice develops among people who, in the real world, are already part of a given community of practice, i.e. practise the same trade or share the same working conditions. The community of practice emerges from collective activity. It does not constitute an aim in itself but is the result of the involvement of individuals in the actions of professional practice. For each individual, the virtual community of practice represents a means of investing themselves in the social or professional definition of their trade, to reinforce their professional identity, to enrich or perfect their daily practice while contributing to the practice of the community. For a community of professionals, involvement in a virtual community of practice is a means to make practice explicit, to improve and even to transform it. For the organisation, it is a means of perennialising practices judged desirable, to integrate new members and to maintain the common know-how essential to efficient professional practice.

Since a community of practice does not have a predefined lifespan, nor a specific project which mobilises its energies, it is characterised by a slow evolution and a high capacity to integrate new members.

Activity. In contrast with the goal-oriented community of interest, whose principal challenge is to build a knowledge system relevant to the project by drawing upon multiple fields of expertise, the challenge for a community of practice is to develop and enrich professional practice by sharing and pooling complementary knowledge among its members. While taking part in the activity of the virtual community of practice, its members become aware of the fact that they share concerns and common interests, that they partake of the same knowledge system and that their exchanges are centred on the problems of their day-to-day work.

The reification unfolds in the creation and in the circulation of 'boundary objects' (Star, 1989) that reinforce the sense of belonging of the members and facilitate the constitution of the identity of the community. These boundary objects convey collective and normalised knowledge, which enable the generation of new knowledge and coordination of the activity. By producing these objects, the communities outline their zone of influence and can define themselves in relationship to other communities or to the institution or organisation. Within a community of practice, both participation and non-participation (marginal and peripheral participation) are sources of learning. By accepting peripheral activities or the expression of marginal points of view, the community grants itself opportunities to explore new possibilities of action and learning.

Learning and identity construction. For the members, the community of practice allows the development of a collective identity by answering the questions 'who are we?' and 'who are we not?' This construction of professional identity is closely related to the learning process that allows the evolution of practices as well as the integration of new members. Learning by practice manifests itself in the capacity to invent forms of involvement, to develop collaborative relationships, to elaborate a shared repertory in continuity with past practices but also to build new artefacts and new interpretative frameworks. Such learning can take place only if certain conditions are met, namely the existence of a common practice individuals can identify with; common, recognised and shared needs; the acceptance of change through contact with others; and the goal to gain new or to improve competencies. 
An example of a community of practice: $H$-français. A good example of the activity of a virtual community of practice is that of the history/geography teachers of $\mathrm{H}$ Français, that is reported in the longitudinal study of Pascaud (2002). H-Français constitutes one of oldest teachers' virtual communities in France. Created in 1996 from the individual initiative of two teachers, it currently includes 1300 teachers, most of whom teach history/geography at high-school and college levels. The growth of the community resulted from unconstrained membership of the teachers. Its objective is to create an information exchange forum on professional innovations and on contextualised professional practices.

Typically, the exchanges within this community of practice are centred on professional practice and are essentially of three types: general, disciplinary, professional or technical information; exchanges on teaching activity along the school year; specific requests calling upon expert knowledge. These exchanges, aiming to define and to assert the identity of the community, testify to the search for and of the negotiation of a common interpretative framework linked with work performance. However, the participation of the members is not quite the same as of those in a community of practice which can usually be qualified by three levels of participation: intense, active and peripheral (Wenger et al., 2002). Pascaud (2002) shows that over a 7-month period, the activity of the community was dominated by the five founding members (25\% of messages), whose intense participation corresponds to the core group proposed by Wenger et al., (2002) and who play a role of coordination and moderation. Pascaud's analysis reveals no second level of active participation. Rather, most subscribers on the list remain silent, as fits the definition of the third level of participation, or 'peripheral participation' $3.8 \%$ of the registered members send on average one message per month; $28 \%$ sent between one and five messages during this period).

The construction process of the internal identity of this community was reflected in the exchanges when the imbalance of the addressed subjects (in favour of geography) was questioned. Another internal identity crisis took place and was solved by the decision to exclude political and commercial issues from the list. The construction of the external identity was also framed in terms of the representativeness of the profession by the list (since the list gathers $5 \%$ or the total number of history/geography teachers in France) and the development of the relations with other elements of professional activity (associations, journals, academic institutions). The activity of this community of practice enabled its members to produce solutions to professional tensions, to explore new opportunities for action and to constitute 'a truly life-long teacher education vector'.

\section{Discussion and conclusion}

The following table summarises the characteristics of the four types of virtual communities just described.

The study set out to show that virtual communities are varied and that they are characterised by their social context of emergence and evolution, which determines the specific activity of each one. The various types of communities stand on the continuum expressing the relationship between the strength of the social bond and the intentionality of the gathering. The dynamics inherent in the life of a community often leads to the evolution of these parameters and, consequently, to a change in the type of activity or to the emergence of another type of community. 
Consequently, the participation in these communities leads to various kinds of learning. Subsequently, to understand and evaluate the activity and the learning realised in virtual communities, evaluation criteria must take into account their social context of emergence and their given goal, their evolutionary aspects as well as the activity they carry out. To analyse the virtual community's activity, it is necessary to concurrently take into account the process of participation (communication and action) and the process of reification (use and production of intermediary objects). It should be stressed here that the perceptible disappointment of many researchers following the evaluation of the productivity of virtual communities often comes from their implicit or explicit expectations. However, if these expectations cannot be satisfied, it is probably because they are concerned by aspects of the activity of the community that it does not or cannot have.

Table 1. Principal descriptors of the four types of virtual communities.

\begin{tabular}{|c|c|c|c|c|}
\hline & $\begin{array}{l}\text { Community of } \\
\text { interest } \\
\text { of interest }\end{array}$ & $\begin{array}{l}\text { Goal-oriented } \\
\text { community }\end{array}$ & $\begin{array}{l}\text { Learners' } \\
\text { community }\end{array}$ & $\begin{array}{l}\text { Community of } \\
\text { practice }\end{array}$ \\
\hline $\begin{array}{l}\text { Social } \\
\text { context of } \\
\text { emergence }\end{array}$ & $\begin{array}{l}\text { Gathering around a } \\
\text { common topic } \\
\text { of interest. }\end{array}$ & $\begin{array}{l}\text { Created to carry out } \\
\text { a specific mandate. }\end{array}$ & $\begin{array}{l}\text { Pedagogical activity } \\
\text { proposed by the } \\
\text { instructor. }\end{array}$ & $\begin{array}{l}\text { Stems from an } \\
\text { existing, real } \\
\text { community of practice. }\end{array}$ \\
\hline Activity & $\begin{array}{l}\text { Information } \\
\text { exchange. }\end{array}$ & $\begin{array}{l}\text { Sharing of diverse } \\
\text { perspectives and } \\
\text { production of objects } \\
\text { commissioned by } \\
\text { the mandate. }\end{array}$ & $\begin{array}{l}\text { Participation to the } \\
\text { realisation of a } \\
\text { collective project. }\end{array}$ & $\begin{array}{l}\text { Professional practice } \\
\text { development through } \\
\text { sharing knowledge } \\
\text { among members. }\end{array}$ \\
\hline Learning & $\begin{array}{l}\text { Knowledge } \\
\text { construction for } \\
\text { individual use. }\end{array}$ & $\begin{array}{l}\text { Knowledge } \\
\text { construction from } \\
\text { diverse knowledge } \\
\text { systems towards } \\
\text { collective use. }\end{array}$ & $\begin{array}{l}\text { Knowledge } \\
\text { construction by } \\
\text { carrying out social } \\
\text { situated activities. }\end{array}$ & $\begin{array}{l}\text { Appropriation of } \\
\text { new practices } \\
\text { and development } \\
\text { of involvement. }\end{array}$ \\
\hline
\end{tabular}

There are limits to this work. It is merely a sketch for the development of a consistent theoretical framework that should enable:

- a better definition of the characteristics and the diversity of virtual communities, as well as the relationship between socialisation and the learning they enable;

- an enhanced description of the processes that lead to learning; and

- a finer discrimination of the various types of learning.

The availability of such a theoretical framework constitutes a preliminary stage of the elaboration of analysis and evaluation methodologies of the activity and of the learning that takes place in virtual communities and imposes itself as a precondition for the development of methods, instruments and tools able to effectively support the activity of virtual communities.

\section{References}

Aubé, M. \& David, R. (2000) 'Darwin's world': Hypermedia technology to enhance scientific thinking in the kids. In Proceedings of ED-MEDIA 2000: World Conference on Educational Multimedia, Hypermedia \& Telecomunications, (eds. J. Bourdeau \& R. Heller) pp. 1212-1213. AACE, Charlottesville, VA.

Barab, S.A. \& Duffy, T. (2000) From practice fields to communities of practice. In Theoretical Foundations of Learning Environments (eds. D. Jonassen \& S.M. Land) pp. 25-56. Lawrence Erlbaum Associates, Mahwah, NJ.

Benoit, J. (2000) La Communauté de Pratique En Réseau. [accessed: 14/2/2001] http://www.tact.fse.ulaval.ca/ang/html/cp/accueil.htm 
Breton, P. (1995) L'utopie de la Communication: L'émergence de L'homme Sans Intérieur. La Découverte, Paris.

Bruner, J. (1996) The Culture of Education. Harvard University Press, Cambridge.

Charlier, B. \& Peraya, D. (2002) Technologie et innovation en pédagogie. Dispositifs Innovants de Formation Pour L'enseignement Supérieur. De Boeck, Bruxelles.

Crook, C. (1999) Computers in the community of classrooms. In Learning with Computers Analysing Productive Interaction (eds. K. Littleton \& P. Light) pp. 102-117. Routledge, London.

CTGV (1990) Anchored instruction and its relationship to situated cognition. Educational Researcher, 19, 6, 2-10.

CTGV (1991) Technology and the design of generative learning environments. Educational Technology, 31, 5, 34-40.

CTGV (1993) Anchored instruction and situated cognition revisited. Educational Technology, 33, 3, 52-70.

Daele, A. (2002) Learn-Nett - Learning Network for Teachers. In Étude Des Communautés Délocalisées D'enseignants. Rapport PNER (Programme Numérisation pour l'Enseignement et la Recherche) (eds. A. Daele \& B. Charlier) pp. 65-72. Fondation Maison des Sciences de l'Homme, Paris.

Engeström, Y. (1987) Learning by Expanding: an Activity-Theoretical Approach to Developmental Research. Orienta-Konsultit, Helsinki.

Fischer, G. (2001) Communities of Interest: Learning through the interaction of Multiple Knowledge Systems'. In Proceedings of the 24th IRIS Conference (eds. S. Bjornestad, R. Moe, A. Morch \& A. Opdahl) pp. 1-14. Department of Information Science, Bergen. [accessed 2/3/2002] http://www.cs.colorado.edu/ gerhard/papers/iris24.pdf .

Gordin, N.G., Gomez, L.M., Pea, R.D. \& Fishman, B.J. (1996) Using the World Wide Web for building the learning communities in K-12. Journal of Computer-Mediated Communication, 2, 3. http://jcmc.huji.ac.il/vol2/issue3/gordin.html

Greeno, J.G., Collins, A.M. \& Resnick, L.B. (1996) Cognition and learning. In Handbook of Educational Psychology (eds. D. Berliner \& R. Calfee) pp. 15-46. Macmillan, New York.

Greeno, J.G. \& Moore, L.M.J. (1993) Situativity and symbols. (Response to Vera and Simon). Cognitive Science, 17, 49-59.

Henri, F. \& Lundgren-Cayrol, K. (2001) Apprentissage collaboratif à distance. Pour comprendre et concevoir les environnements d'apprentissage virtuels. Presses Universitaires du Québec, Sainte Foy, Québec.

Hung, D. \& Chen, D.T. (2002) Understanding how thriving internet quasi-communities work: distinguishing between learning about and learning to be. Educational Technology, 42, 1, 23-27.

Koschmann, T. (ed.) (1996) CSCL: Theory and practice of an emerging paradigma. Lawrence Erlbaum Associates, Hillsdale, NJ.

Laferrière, T. \& Grégoire, R.I. (1999) Réseau Scolaire Canadien (Rescol). Apprendre ensemble par projet avec l'ordinateur en réseau. Guide à l'intention des enseignants et des enseignantes. http://www.tact.fse.ulaval.ca/ang/html/projectg.html [accessed 14/2/2001].

Lave, J. \& Wenger, E. (1990). Situated Learning: Legitimate Peripheral Participation. Cambridge University Press, Cambridge.

Leontiev, A.N. (1981) Problems of the development of the mind. (anonymous translation). Progress, Moscow. (Original work published in Russian, 1959).

Lévy, P. (2000) World Philosophie. Odile Jacob, Paris.

Mercer, N. \& Wegerif, R. (1999) Is ‘exploratory talk' productive talk? In Learning with Computers Analysing Productive Interaction (eds. K. Littleton \& P. Light) pp. 79-101. Routledge, London.

Nichani, M. \& Hung, D. (2002) Can a community of practice exist online? Educational Technology, 42, 4, 49-54.

(C) 2003 Blackwell Publishing Ltd, Journal of Computer Assisted Learning, 19, 474-487 
Papert, S. (1993). The Children's Machine Rethinking School in the Age of the Computer. Basic Books, New York.

Pascaud, D. (2002) La liste H-français: une liste professionnelle à la croisée des chemins. In Étude Des Communautés Délocalisées D'enseignants. Rapport PNER (Programme Numérisation pour l'Enseignement et la Recherche) (eds. A. Daele \& B. Charlier) pp. 7379. Fondation Maison des Sciences de l'Homme, Paris.

Pea, R.D. (1993) Seeing what we build together: distributed multimedia learning environments for transformative communications. Journal of the Learning Sciences, 3, 3 , 285-299.

Rheingold, H. (1993) The Virtual Community. Massachusetts: Addison-Wesley, 1993.

Rittel, H. (1984) Second-generation design methods. In Developments in Design Methodology (ed. N. Cross) pp. 317-327. John Wiley, New York.

Roth, W. (1996) Knowledge diffusion in a grade 4-5 classroom during a unit on civil engineering: An analysis of a classroom community in terms of its changing resources and practices. Cognition and Instruction, 14, 2, 179-220.

Scardamalia, M. \& Bereiter, C. (1991) Higher levels of agency in knowledge building: a challenge for the design of new knowledge media. Journal of the Learning Sciences, $\mathbf{1}$ 37-68.

Schwartz, D.L. (1999) The productive agency that drives collaborative learning. In Collaborative Learning Cognitive and Computational Approaches (ed: P. Dillenbourg) pp. 197-217. Elsevier Science, Oxford.

Snow, C.P. (1993) The Two Cultures. Cambridge University Press, Cambridge.

Star. L. (1989) The structure of Ill-Structured Solutions: Boundary Objects and Heterogeneous Distributed problem Solving. In Distributed Artificial Intelligence, Vol. 2, (eds. L. Gasser \& M.N. Huhns) pp. 37-54. Morgan Kaufman Publishers, San Mateo, CA.

St-Arnaud, Y. (1989) Les petits groupes. Participation et communication. Presses de l'Université de Montréal et Les Éditions du CMI, Montréal.

Trentin, G. (2001) From formal training to communities of practice via network-based learning. Educational Technology, 41, 2, 5-14.

Weinreich, F. (1997) Establishing a point of view toward virtual communities. CMC Magazine. March. http://www.december.com/cmc/mag/1997/feb/wein.html [accessed 20/9/2001].

Wenger, E. (1998) Communities of Practice Learning, Meaning and Identity. Cambridge University Press, Cambridge.

Wenger, E., McDermott, R. \& Snyder, W. (2002) Cultivating Communities of Practice. Harvard Business School Press, Boston.

Whittaker, S., Terveen, L., Hill, W. \& Cherny, L. (1998) The dynamics of mass interaction. In Proceedings of the 1998 ACM Conference on Computer Supported Cooperative Work. pp. 257-264. ACM Press, New York.

http://www.shef.ac.uk/uni/academic/l-M/is/people/stafpage/whittake/cscw98-published.pdf 